\section{The fairer science}

\section{RoyPorter}

Nature's Body: Gender in the Making of Modern Science. By Londa Schiebinger. Beacon: 1993. Pp. 289. \$25.

THE rise of modern science meant the discrediting of the old human-centred subjective cosmos beloved of mediaeval people, which attributed soul and feelings to everything. Its gushing, poetic anthropomorphism was replaced by a worldview that was severely objective: nature was just matter in motion, governed by mathematical laws, studied by neutral scientists. Or so, at least, runs the conventional textbook story of the scientific revolution. But such readings are far too simple, argues Londa Schiebinger in her crisp and well documented account of Linnaean natural history and early anthropology. Science did not suddenly become value-neutral: it long continued to incorporate ideas that saw the kingdoms of nature through human categories (as the metaphor of 'kingdom' itself reveals).

"Leaves . . . serve as bridal beds . . . perfumed with so many soft scents that the bridegroom with his bride might there celebrate their nuptials with so much the greater solemnity." Who is writing here? Some bard waxing lyrical about a tryst in an arbour? No, it's none other than Linnaeus, the eighteenth-century founder of modern taxonomy, proudly displaying his understanding of recently discovered plant sexuality and describing the fertilization of flowers. Ah, but that's just a rhetorical flourish, it might be objected. Not so, however. For the truth is that Linnaean botany is saturated with sexual allusions and judgements more appropriate to human ethics than to nature. Linnaeus made the key to his sexual system what he termed the nuptiae plantarum the marriages of plants. One class of plants (Linnaeus's monandria) practised monogamy. Other plants had twenty or more 'husbands' (Linnaeus's term) sharing the marriage bed (petals of the same flower). In diverse arrangements of stamens and pistils, plant husbands of the class significantly labelled polygamia lived with 'wives' and 'harlots' or 'concubines'. The writings of Linnaeus, and his British popularizers such as Erasmus Darwin, systematically project onto botany the idioms of human eroticism and sexual mores - as outraged moralists protested.

And nowhere is this so conspicuous as in another Linnaean coinage: mammals. Classification after Aristotle had distinguished 'higher creatures' from fish, amphibians and birds by calling them 'quadrupeds'. But naturalists grew aware that four-footedness was an unsatisfactory descriptor, for whales - and humans - obviously shared such 'higher' features as warm-bloodedness, the four-chambered heart and hairiness. But in the end the distinguishing feature that clinched the classification Linnaeus devised was the possession of breasts (mammae). Why? Not because there was no other possibility, Schiebinger reasonably argues we could all be called Pilosa (the hairy ones); but in part because the idea of mothers suckling their young achieved tremendous kudos within human culture in the enlightenment era. Rejecting the prevalent fashion of wet-nursing, Linnaeus made his wife put all their seven children to the breast.

In discussing binomial botany and the naming of Mammalia, Schiebinger has no quarrel with the science produced. Her aim is merely to insist that to grasp why certain scientific ideals jell at certain times, it's not enough to think in terms of 'discoveries': we must have a view to the outlooks, interests - and sex - of the naturalists involved. Several of the chapters of her wide-ranging book, however, focus on areas of inquiry where science lent its authority to gross bias or bigotry. One was the creation of racial stereotypes. An age of exploration produced greater awareness of 'primates' (another Linnaean coinage) and of the diversities of mankind. Not surprisingly, strenuous efforts were made to construct typologies of difference. Inevitably this entailed uncertainties about the relationships of "people of color" (Schiebinger's phrase) to gorillas, chimpanzees and the various 'pongos' and 'jockos' that figured in the travel literature. The superiority of 'Caucasians' (another new coinage) might be reinforced by the downgrading of blacks towards the apes - a process aided through the rather whimsical tactic of attributing a surprisingly high degree of 'savvy' and civilization to orangutans. In Thomas Peacock's satirical novel, Melincourt, Sir Oran Haut-ton is an orangutan who rises in society and (thanks to his silence) becomes a highly esteemed member of parliament.

Alongside 'people of color', early anthropologists stigmatized women, often grotesquely. Black women were often represented, in travellers' tales, as copulating with gorillas (hence miscegenation). Their supposed sagging pendulous breasts became objects of disdain, derision and prurience for male naturalists, as did the notorious elongated labia minora of Hottentot women. Once the so-called 'Hottentot Venus' was brought to Europe early in the nineteenth century, it seemed as if the whole community of naturalists

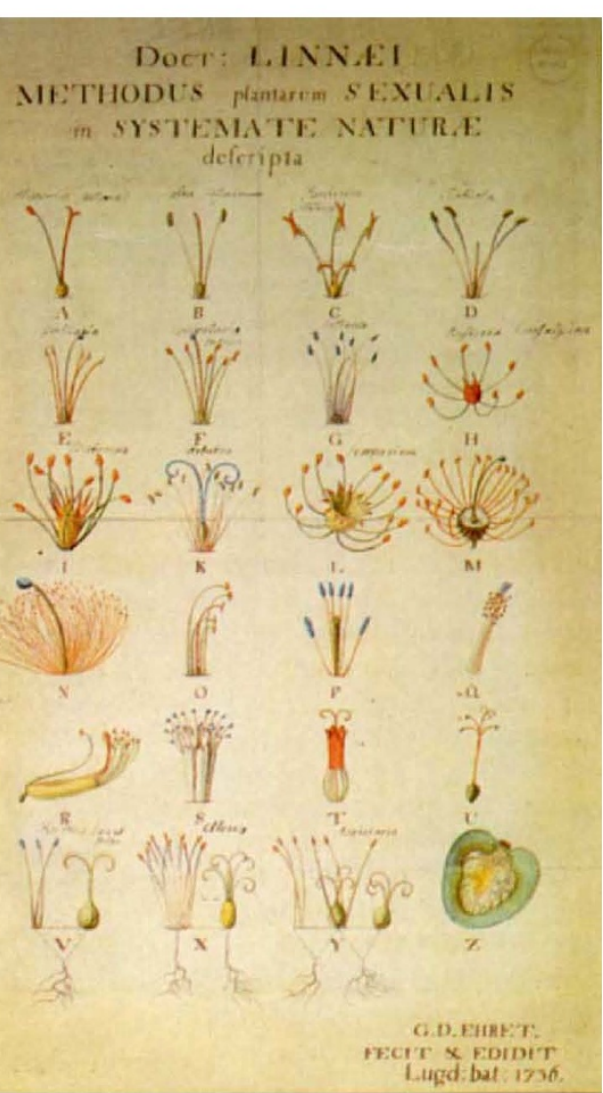

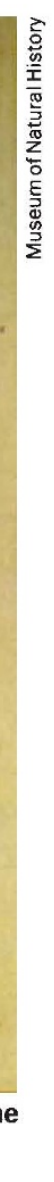

was gawping, purely out of love of science, at the genitalia of black women.

A certain (perfectly justifiable) indignation informs Schiebinger's book. Science has much to answer for in its creation of successions of stigmatizing stereotypes, supposedly 'natural' but in reality the projection of prejudice. But she is no less sensitive to the complexities and the genuine dilemmas of scientific classification. Science (as the case of Sir Oran shows) created positive as well as negative images; blacks and women also had their defenders, and a few naturalists, such as Blumenbach, were deeply circumspect about drawing premature conclusions about the map of mankind. Moreover, science also punctured certain traditional myths, not least when Linnaeus actually set Homo sapiens among the primates.

Seeing nature through social spectacles remains a problem today, as ethnic and sex differences continue to be politically explosive and sociobiology creates new anthropomorphic languages - with talk, for instance, of genetic investment strategies. Schiebinger's incisive book draws timely attention to the critical roles of language, metaphor and ideology in the development of science. Anthropomorphization was never eradicated: it is our job to be alert to it.

Roy Porter is in the Wellcome Institute for the History of Medicine, 183 Euston Road, London NW1 2BN, UK. 